\title{
PERANCANGAN PERPUSTAKAAN UMUM DI SAWAHLUNTO DENGAN PENDEKATAN ARSITEKTUR KONTEKSTUAL
}

\section{DESIGNING PUBLIC LIBRARIES IN SAWAHLUNTO WITH A CONTEXTUAL ARCHITECTURAL APPROACH}

\author{
Rahmat Wendri11), Mira Dharma S2) \& Wahyu Hidayat ${ }^{32 *}$ \\ 1)Mahasiswa Prodi Arsitektur Fakultas Teknik Universitas Negri Riau, Indonesia \\ 2, 3) Dosen Prodi Arsitektur Fakultas Teknik Universitas Negri Riau, Indonesia \\ Diterima: Februari 2021; Disetujui: Maret 2021; Dipublikasi: April 2021 \\ *Corresponding author: rahmat.wendri@student.unri.ac.id
}

\begin{abstract}
Abstrak
Sawahlunto merupakan salah satu kota di provinsi Sumatera Barat yang terkenal dengan bangunanbangunan Belandanya dan juga salah satu aset di Indonesia yang telah di tetapkan menjadi kota pusaka dan warisan dunia oleh Unesco pada tahun 2019. Akan tetapi kota Sawahlunto tidak memiliki perpustakaan umum yang layak, dikarenakan perpustakaan umum sebelumnya tidak mepunyai fasilitas-fasilitas yang memadai dan tidak dapat menampung kegiatan-kegiatan masyarakat dalam mencari informasi. Tujuan dari perancangan perpustakaan umum ini agar mampu memberikan fasilitas dan pelayanan kepada masyarakat dan memudahkan masyarakat dalam mencari informasi yang mereka inginkan, serta dengan penerapan arsitektur kontekstual dapat menjaga dan memperkuat karakter kota pusaka Sawahlunto dan juga bangunan-bangunan yang ada di lingkungan sekitarnya. Metode penelitian yang digunakan berupa pengamatan, wawancara dan data literatur. Pada perancangan ini menerapkan konsep Alam Takambang jadi Guru yang didapatkan dari keterkaitan fungsi serta tema pada rancangan yang diterapkan pada gubahasan massa dan fasad bangunan.
\end{abstract}

\section{Kata Kunci : Perpustaaan; Arsitektur Kontekstual; Sawahlunto}

\begin{abstract}
and also one of the assets in Indonesia which has been designated as a heritage and world heritage city by Unesco in 2019. However, Sawahlunto city does not have a proper public library, because the previous public library did not have adequate facilities and could not accommodate community activities in finding information. The purpose of this public library design is to be able to provide facilities and services to the community and facilitate the public in finding the information they want, and by applying contextual architecture can maintain and strengthen the character of the heritage city of Sawahlunto and also buildings in the surrounding environment. The research method used in the form of observations, interviews and literature data. In this design applying the concept of Nature Takambang to be a teacher that is obtained from the interrelationship of functions and themes in the design applied to the composition of the masses and building facades.
\end{abstract}

Keywords: Library; Contextual Architecture; Sawahlunto 
How to Cite : Rahmat Wendri, Mira Dharma, Wahyu Hidayat (2021). Perancangan Perpustakaan Umum dengan Pendekatan Arsitektur Kontekstual. JAUR (Journal of Architecture and Urbanism Research). 4 (2): 149-157 


\section{PENDAHULUAN}

Perpustakaan umum merupakan suatu ruang atau tempat yang dibangun khusus untuk kepentingan masyarakat dalam memenuhi informasi yang diperlukan dan memamfaatkan segala sesuatu yang terdapat di perpustakaan yang telah di sediakan tanpa membedakan latar belakang, suku, agama, pendidikan dan sebagainya (Wiji Suwarno, 2007). Di dalam ruang perpustakaan tersebut terdapat berbagai macam bahan cetak seperti bukubuku, majalah dan sebagainya, dan ada juga non cetak yaitu seperti media audiovisual berupa kaset, film dan sebagainya. Para pengguna dapat mencari informasi lewat buku-buku yang ada di perpustakaan, dikarenakan dari dulu hingga sekarang perpustakaan sebagai tempat yang menyediakan berbagai informasi.

Perpustakaan mempunyai peran yang sangat penting bagi masyarakat umum. Khususnya masyarakat Sawahlunto, yang mana banyaknya minat baca masyarakat dalam menambah ilmu pengetahuan baik itu anak-anak, remaja maupun dewasa. Sawahlunto merupakan salah satu Provinsi yang memiliki minat baca yang cukup banyak.

Kota Sawahlunto memiliki luas wilayah 27.345 Ha dan mempunyai penduduk 62.524 orang. Sawahlunto juga dikenal sebagai salah satu kota Kolonial yang ada di Sumatera Barat yang memiliki 4 kecamatan yaitu kecamatan Talawi, kecamatan Barangin, kecamatan lembah Sengar dan kecamatan Silungkang. Akan tetapi dengan jumlah penduduk yang cukup banyak dan juga minat bacanya, sangat di sayangkan masyarakat Sawahlunto tidak mempunyai perpustakaan umum yang layak, dikarenakan perpustakaan umum sebelumnya hanya memiliki luasan bangunan $25 \times 10 \mathrm{~m}^{2}$ dan itupun bangunan tersebut bekas gedung bioskop yang dijadikan sebagai perpustakaan umum di Sawahlunto. Menurut Badan Standarisasi Naisional luasan perpustakaan umum kabupaten atau kota yaitu sekurang kurangnya $600 \mathrm{~m}^{2}$. Oleh karena itu dibutuhkan perpustakaan umum yang layak dan dapat menampung kegiatan- kegiatan masyarakat dalam mencari informasi dan dapat menambah ilmu pengetahuan.

Keberadaan kota Sawahlunto merupakan salah satu aset di Indonesia yang telah ditetapkan menjadi kota pusaka dan warisan dunia oleh The United Nations Educational, Scientific and Cultural Organization (UNESCO) pada tahun 2019, yang mana di Sawahlunto terdapat banyak bangunan-bangunan Kolonial Belanda. Adapun bangunan Kolonial yang terdapat di Sawahlunto seperti bangunan Gluck Auf atau Gedung Pusat Kebudayaan, Hotel Ombilin, PT Batu bara Bukit Asam, Kantor Pengadaian, Gereja, Gudang Ransoem, Perpustakaan Umum dan sebagainya. Agar dapat menjaga karakter-karakter bangunanan yang ada dilingkungan kota Sawahlunto yaitu dengan menggunakan tema Arsitektur Kontekstual.

Arsitektur Kontekstual merupakan desain yang memiliki kaitan-kaitan visual dengan lingkungan sekitar, sehingga menciptakan efek visual yang menyatu dan dapat memperkuat karakter lingkungan setempat.

Maka dari itu untuk Perancangan Perpustakaan umum di Sawahlunto ini menggunakan Arsitektur Kontekstual, dikarenakan agar dapat memperkuat dan juga menjaga karakter kota Sawahlunto sehingga bangunan tersebut selaras dengan lingkungan sekitar. 
Adapun permasalahan yang akan dihadapi dalam perancangan Perpustakaan Umum di Sawahlunto, sebagai berikut:

Bagaimana

merumuskan

kebutuhan dan program ruang dalam perancangan Perpustakan di Sawahlunto?

Apa saja karakteristik-karakteristik bangunan kontekstual yang ada di Sawahlunto?

Bagaimana merumuskan konsep perancangan Perpustakaam Umum di Sawahlunto?

Berdasarkan permasalahan tersebut didapatlah tujuan sebagai berikut:

Menghasilkan

perancangan

Perpustakaan Umum yang sesuai fungsi baik ruang dalam maupun luar sehingga menciptakan ruang yang optimal untuk pengguna.

Merancang Perpustakaan Umum yang nyaman bagi pengunjung perpustakaan.

Untuk dapat mengaplikasikan dengan ciri-ciri Arsitektur Kontekstual pada desain Perpustakaan Umum yang selaras dengan lingkungan setempat.

\section{METODE PENELITIAN}

Metode yang digunakan dalam perancangan Perpustakaan Umum di Sawahlunto dengan pendekatan Arsitektur Kontekstual yang mengambil kekhasan bangunan yang ada di lingkungan setempat.

Strategi perancangan pada Perpustakaan Umum ini memiliki beberapa tahapan antara lain dimulai dengan survey, analisa tapak, analisa fungsional, membuat program ruang, penzoningan, konsep, sirkulasi, bentukan massa, sistem struktur, denah, lansekap dan fasad hingga mendapatkan hasil desain.
Metode pengumpulan data terbagi menjadi 2 jenis, Data primer yaitu metode pengamatan langsung terhadap obyek berupa survey lapangan dan dokumentasi, sedangkan Data sekunder merupakan data yang diperoleh dari sumber-sumber ilmiah berupa studi pustaka dan studi banding.

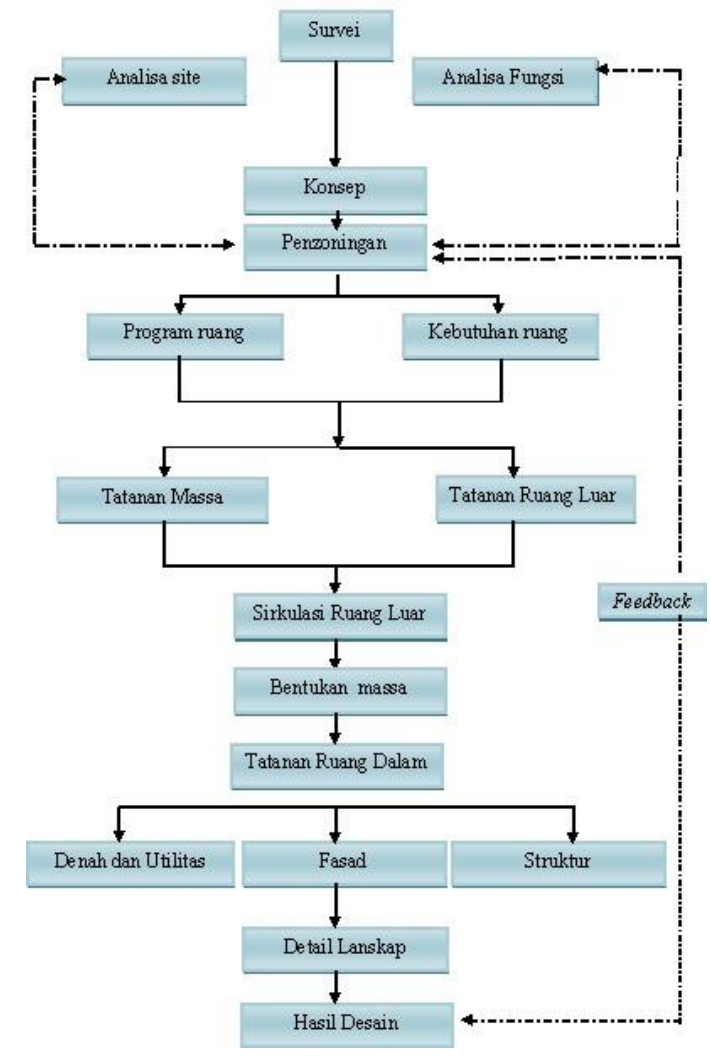

Gambar 1. Bagan Alur Perancangan

\section{PEMBAHASAN}

Lokasi perancangan ini terletak pada jalan Yos Sudarso, kecamatan Lembah Segar, kota Sawahlunto. Pada area ini merupakan tempat strategis untuk merancang Perpustakaan. Dimana pada kawasan ini juga terdapat institusi pendidikan, gedung, kebudayaan dan museum. Dengan data fisik luas lahan $\pm 8000 \mathrm{~m}^{2}$, koefisien dasar bangunan $30 \%$ dengan kondisi kontur relatif datar dan kondisi lahan saat ini adalah lahan kosong. 


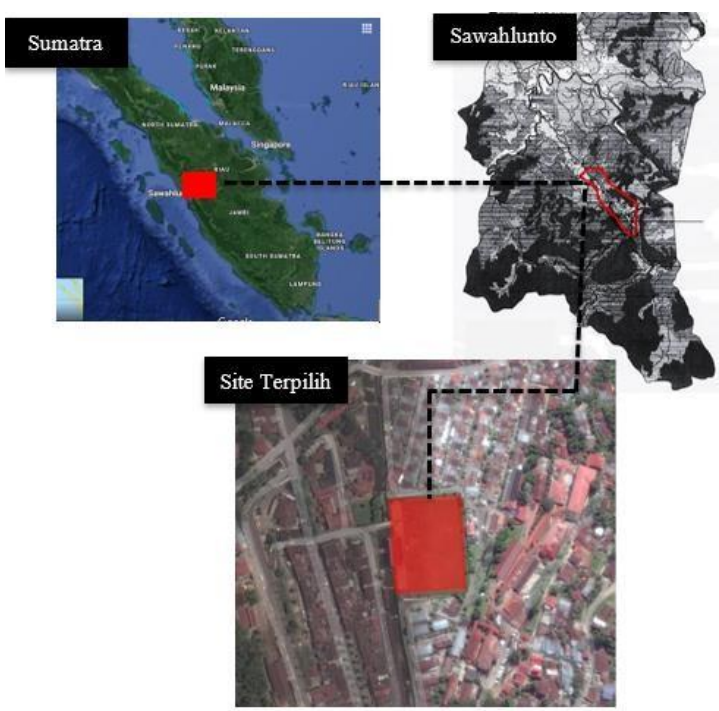

Gambar 2. Lokasi Site

Analisa kegiatan pengguna bangunan dalam kebutuhan ruang yang diperlukan untuk bangunan Perpustakaan Umum di Sawahlunto ini yaitu memaksimalkan fungsi, terbagi dalam tabel sebagai berikut:

Tabel 1. Kebutuhan Ruang

\begin{tabular}{|c|c|c|}
\hline $\begin{array}{l}\text { Kebutuhan } \\
\text { Ruang }\end{array}$ & Jenis Kegiatan & Luasan \\
\hline $\begin{array}{c}\text { Ruang } \\
\text { Fasilitas } \\
\text { Utama }\end{array}$ & $\begin{array}{l}\text { Ruang baca, } \\
\text { Ruang diskusi } \\
\text { dan Tempat } \\
\text { pemimjaman } \\
\text { buku atau } \\
\text { pengembalian }\end{array}$ & $1.835 \mathrm{~m}^{2}$ \\
\hline $\begin{array}{c}\text { Ruang } \\
\text { Fasilitas } \\
\text { Pendukung }\end{array}$ & $\begin{array}{l}\text { Toko buku, } \\
\text { dan kafeteria }\end{array}$ & $1.36,5 \mathrm{~m}^{2}$ \\
\hline $\begin{array}{c}\text { Ruang } \\
\text { Fasilitas } \\
\text { Pengelola }\end{array}$ & $\begin{array}{l}\text { Pengelola } \\
\text { Bangunan }\end{array}$ & $754 \mathrm{~m}^{2}$ \\
\hline Servis & Servis & $366,3 \mathrm{~m}^{2}$ \\
\hline \multicolumn{2}{|c|}{$\begin{array}{c}\text { Luasan total kebutuhan ruang } \\
\text { bangunan }\end{array}$} & $4.786,8 \mathrm{~m}^{2}$ \\
\hline
\end{tabular}

Penzoningan pada Perancangan Perpustakaan Umum di Sawahlunto terbagi beberapa zoning sebagai berikut:

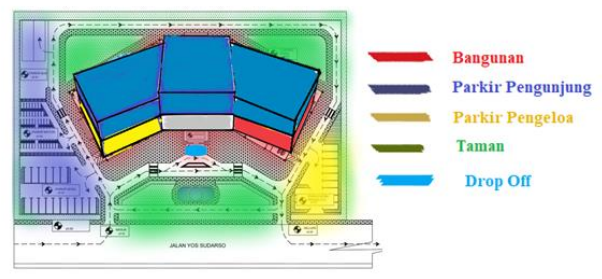

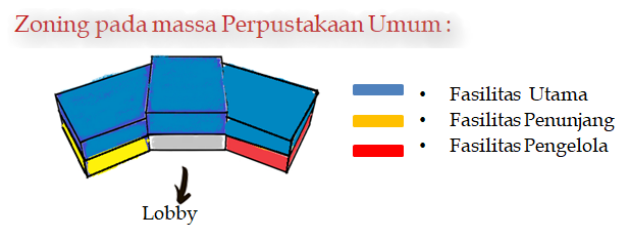

Gambar 3. Zonasi Perancangan

Perancangan Perpustakaan Umum di Sawahlunto ini menerapkan ciri-ciri Arstektur Kontekstual menurut C. Blolin (1980) yang di jelaskan sebagai berikut:

Adanya pengulangan motif dari desain bangunan sekitarnya.

Tabel 2. Penerapan Gable

\begin{tabular}{|l|l|l|}
\hline Penerapan & Sketsa & \begin{tabular}{l} 
Keterangan \\
\hline Gable
\end{tabular} \\
\hline & $\begin{array}{l}\text { 1).Atap } \\
\text {-Bentuk atap } \\
\text { Plana dengan } \\
\text { gable bentuk } \\
\text { segitiga. } \\
\text {-Atap } \\
\text { berwarna } \\
\text { kecoklatan, } \\
\text { berbahan } \\
\text { genteng } \\
\text {-Ornamen } \\
\text { horizontal } \\
\text { dan bukaan } \\
\text { pada gable }\end{array}$ \\
\hline
\end{tabular}

Pendekaan baik dari bentuk, ornamen, pola atau irama dan fasade yang memiliki nilai-nilai bangunan bersejarah bertujuan untuk menjaga karakter suatu tempat dan lingkungannya.

Tabel 3. Penerapan Fasad

\begin{tabular}{|l|l|l|}
\hline Penerapan & Sketsa & Keterangan \\
\hline
\end{tabular}




\begin{tabular}{|c|l|l|}
\hline Fasad & $\begin{array}{l}\text { 2).Ornamen } \\
\text { geometris } \\
\text { pada dinding } \\
\text { dan bukan } \\
\text { pada } \\
\text { bangunan. } \\
\text {-Dinding } \\
\text { berwarna } \\
\text { putih dengan } \\
\text { ornamen } \\
\text { geometris } \\
\text { persegi dan } \\
\text { segitiga yang } \\
\text { menjorok } \\
\text { kedalam. } \\
\text {-Terdapat } \\
\text { banyak } \\
\text { bukaan dan } \\
\text { ornamen } \\
\text { fasad } \\
\text { bangunan. }\end{array}$ \\
& \\
&
\end{tabular}

Menggunakan bentuk dasar bangunan yang sama dengan bangunan sekitar, tetapi dapat di atur kembali sehingga nampak perbedaan namun masih selaras dan harmonis.

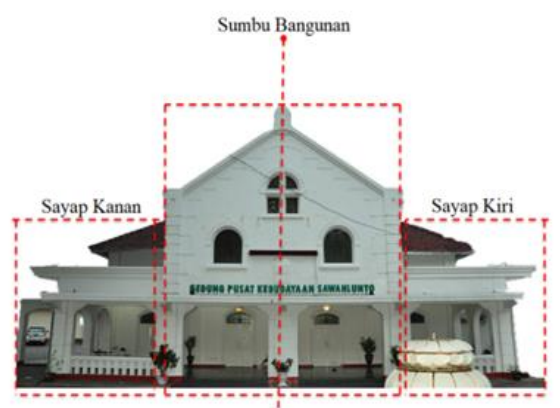

Gambar 4. Bentuk Dasar Bangunan Lingkungan setempat

Adapun bentuk bangunan

Kontekstual yang ada di Kota Sawahlunto, dari tabel disampung dapat dilihat kecendruangan bentukan bangunan yang ada di kota Sawahlunto, sehingga penerapan Kontekstual pada Perancangan Perpustakaan Umum ini menggunakan aspek geometri persegi dan segitiga.

Tabel 4. Bangunan Kontekstual Sawahlunto

\begin{tabular}{|c|c|c|}
\hline $\begin{array}{l}\text { Nama } \\
\text { Bangunan }\end{array}$ & Gambar & Keterangan \\
\hline Gedung & & -Mempunyai \\
\hline Tambang & & tatanan \\
\hline Batu Bara & & simetris. \\
\hline $\begin{array}{l}\text { Ombilin } \\
\text { Sawahlunto }\end{array}$ & 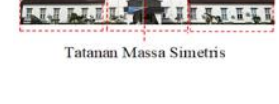 & $\begin{array}{l}\text {-Dipercah } \\
\text { menjadi }\end{array}$ \\
\hline Gedu & & $\begin{array}{c}\text { иматаn yang } \\
\text { lasarkan }\end{array}$ \\
\hline ng Pusat & & $\rightarrow$ arakteristi \\
\hline Kebudayaa & E & $=1$ bangunan \\
\hline $\mathrm{n}$ & & nis \\
\hline $\begin{array}{l}\text { Sawahlunt } \\
\text { o }\end{array}$ & & $\begin{array}{l}\text { Sawahlunto. } \\
\text {-Terdapat }\end{array}$ \\
\hline Rum & & $\begin{array}{l}\text { bu yang } \\
\text { linan }\end{array}$ \\
\hline Dr.Ikhsan & & 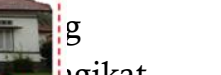 \\
\hline & & $\begin{array}{l}\text { sayao kanan } \\
\text { dan kiri. }\end{array}$ \\
\hline
\end{tabular}

Fasad pada perancangan bangunan Perpustakaan Umum ini akan disesuaikan dengan tema perancangan yaitu arsitektur kontekstual. Pada aspek fisik dengan cara mengadopsi pola fasad yang dominan berada pada lingkungan Sawahlunto yaitu terdiri 
dari gable, jendela, pintu, material, warna dan ornamennya. Selain itu fasad bangunan juga diterapkan sesuai dengan konsep perancangan.

Konsep perancangan Perpustakaan Umum di Sawahlunto ini menerapkan ciriciri bangunan Arsitektur Kontekstual yang ada di Sawahlunto. Bentuk bangunan dibentuk sesuai dengan menggabungkan unsur konsep dan tema. Konsep yang di terapkan yaitu ALAM TAKAMBANG JADI GURU (Bahasa Indonesia: Alam yang terhampar menjadi guru) yang merupakan pepatah dari suku Minangkabau. Artinya adalah umat manusia terkhususnya orang minang pada umumnya harus bisa belajar dari segala kejadian dan fenomena yang ada di alam dan lingkungan setempat.
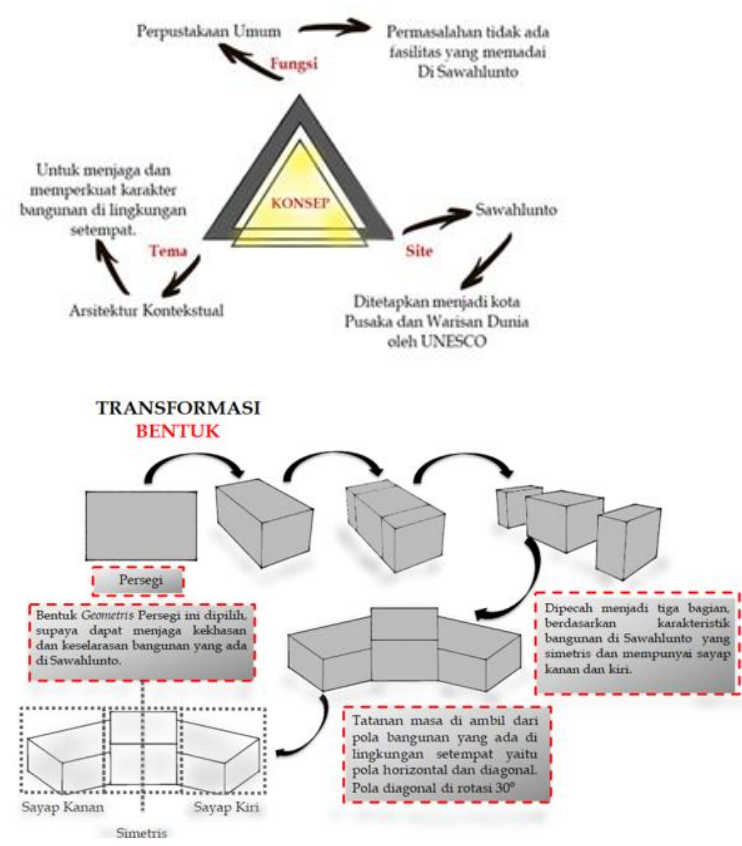

Gambar 5. Transformasi Konsep Rancangan

Bentukan bangunan ini di buat selaras dengan bangunan kontekstual yang ada di lingkungan setempat, agar dapat memperkuat atau menjaga kekhasan bangunan setempat.

Penggunaan material dan Perencanaan struktur. Untuk material yang digunakan adalah beton sebagai material utama akan dipadukan dengan material kayu dan kaca. Untuk material dinding dipilih menggunakan batu bata merah, material lantai menggunakan keramik dan gras blok yang digunakan untuk area parker, material atap menggunakan struktur kayu dan baja.

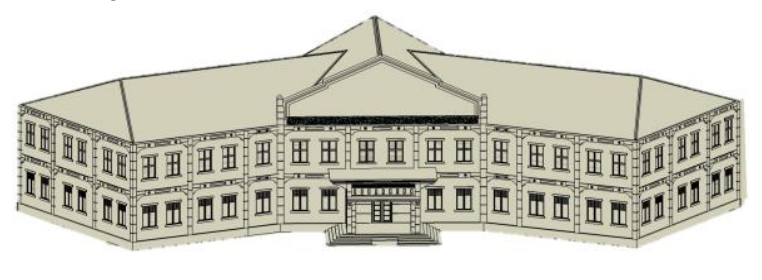

Gambar 6. Penggunaan Beton

Struktur yang akan dipakai yaitu struktur portal dan baja ringan untuk struktur atap yang digunakan banyak digunakan oleh bangunan kontektual yang ada di Sawahlunto.

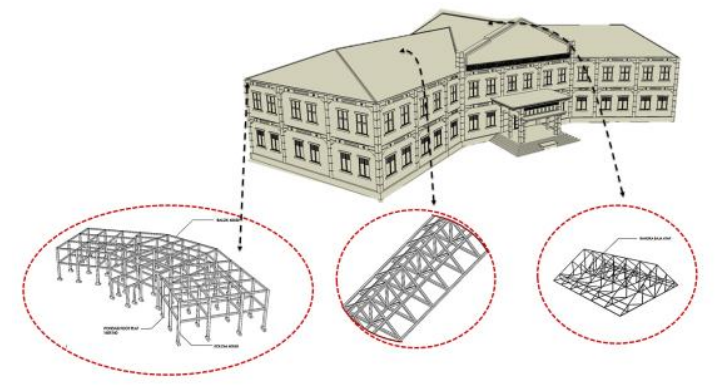

Gambar 7. Penggunaan Struktur Portal dan Baja Ringan

\section{SIMPULAN}

Dari hasil Perancangan Perpustakaan Umum di Sawahlunto dengan pendekatan Arsitektur Kontekstual, maka dapat diambil kesimpulan sebagai berikut:

Perpustakaan Umum di Sawahlunto ini dirancang untuk memberikan wadah berkegiatan bagi pengunjung perpustakaan umum dengan fasilitas-fasilitas yang lengkap dan memadai. Sehingga pengunjung dan 


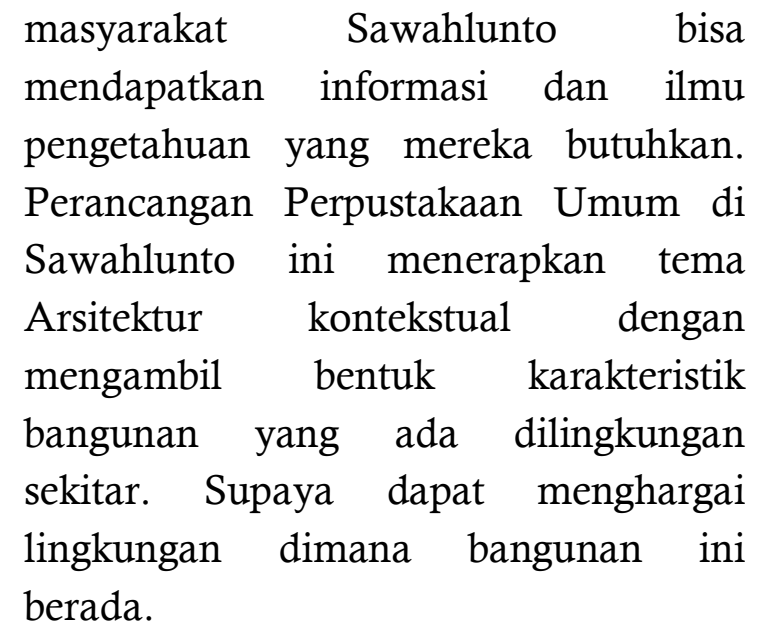

Penerapan konsep Alam

Takambang Jadi Guru di terapkan pada bangunan Perpustakaan Umum di Sawahlunto yaitu berupa fasad yang paling dominan seperti Gable dengan ornamen lumuik hanyuik. Sedangkan konsep massa mengambil bentukan bangunan lingkungan setempat, guna menjaga dan memperkuat karakter kota Sawahlunto

\section{DAFTAR PUSTAKA}

Brolin, C, Brent, 1980, Architecture In Context, Van Nostrand Reinhold Company, New York.

Antoniades, Anthony C., 1992. Poetics of Architecture: Theory of Design. New York: Van Nostrand Reinhold.

Asoka, Andi. Sawahlunto Dulu, Kini dan Esok: Menjadi Kota Wisata Tambang yang Berbudaya. Minangkabau Press. Sumatera Barat.

Sawahlunto Expression in the Rhytms of Stokes : Part Two The Old The Historical.

Erindha Puspitasari, 2010. Perpustakaan di Jogyakarta dengan pendekatan tema Arsitektur Modern. Tugas Akhir di Terbitkan Program Studi Arsitektur Fakultas Teknik Universitas Sebelas Maret, Surakarta.

Riko Mardi Syahputra, 2017. Perancangan Perpustakaan Umum dengan pendekatan tema Pencahayaan Alami. Tugas Akhir di Terbitkan
Program Studi Arsitektur Fakultas Teknik Universitas Riau, Pekanbaru.

Moh Faizin, 2016. Revitalisasi Museum Kereta Api Ambarawa dengan pendekatan tema Arsitektur Kontekstual. Tugas Akhir di Terbitkan Program Studi Arsitektur Fakultas Teknik Universitas Islam Negeri Maulana Malik Ibrahim, Malang.

Departemen Pendidikan Naisional, 2007. UndangUndang Republik Indonesia Nomor 43 tahun 2007 Tentang Perpustakaan, Jakarta: Depdiknas.

Standar Naisional Indonesia SNI 7495:2009, Perpustakaan Umum Kabupaten atau Kota.

Yusuf. (1996). Manajemen Perpustakaan Umum. Jakarta : Universitas Terbuka.

Sulistyo-Basuki.(1993).Penghantar Ilmu perpustakaan, Jakarta : Gramedia Pustaka Utam.

Sutarno, NS. (2004). Manajemen Perpustakaan, Jakarta : Samitra Media Utama.

Sutarno, NS. (2006). Manajemen Perpustakaan, Jakarta. Cv Sagung Seto.

Qalyubi, Syihabuddin. 2007. Dasar-dasar ilmu Perpustakaan dan Informasi. Yogya: Jurusan Ilmu Perpustakaan dan Informasi, UIN Sunan Kalijaga.

Departemen Pendidikan dan Kebudayaan. 2004. Buku Pedoman Perpustakaan Perguruan Tinggi. Jakarta: Departemen Pendidikan dan Kebudayaan.

Rahayuningsih, F. (2007). Pengelolaan Perpustakaan. Yogyakarta: Graha Ilmu.

Lasa HS. (2005). Manajemen Perpustakaan. Yogyakarta : Gama Media.

Darmono. (2001). Manajemen dan Tata Kerja Perpustakaan. Jakarta : Grasindo.

Atmodiwirjo. (2009). Pedoman Tata Ruang dan Perabot Perpustakaan Umum. Jakarta: Perpustakaan Nasional RI.

Ching, F.D.K. 2007. Arsitektur, Bentuk, Ruang, dan Tatanan. Jakarta : Erlangga.

Neufert, Ernst. 2002. Data Arsitektur Jilid 1 Edisi 33. Erlangga, Jakarta.

Peraturan Daerah Kota Sawahlunto Nomor: 7 Tahun 2004 Tentang Izin Mendirikan Bangunan (IMB).

Peraturan Daerah Kota Sawahlunto Nomor: 7 Tahun 2004 Tentang Bangunan Gedung. 